\title{
Hygrothermal performance of bio-based insulation material in wood-frame walls exposed to unintended moisture sources
}

\author{
Bruno Vanderschelden ${ }^{\mathrm{a}}$, Nathan Van Den Bossche ${ }^{\mathrm{a}}$, Marijke Steeman ${ }^{\mathrm{a}}$ \\ a Building Physics Group, Faculty of Engineering and Architecture, Ghent University, Ghent, Belgium
}

\begin{abstract}
The attention for energy performant buildings with a low environmental impact has been growing over the years and as a result, the use of biobased insulation materials as well as wood frame constructions has become more and more prevalent in Belgium and Europe. This research assesses the hygrothermal behavior of bio-based insulation materials, used in wood frame walls. The study concentrates on their durability and thermal performance, when exposed to unintended moisture sources. Two different leakages are looked at: one originating from imperfections in the weathering sealant at the exterior, and a second is introduced due to insufficient air tightness at the interior, causing infiltration of humid indoor air into the wall system and the occurrence of interstitial condensation. Primarily results show the dominant impact of the ventilation rate in the cavity between the masonry outer leaf and the wood frame wall, on the durability and the thermal performance of the structure. Also, there is higher negative impact by exterior leakages on highly absorptive bio-based insulation material compared to the traditional mineral wool setup. Peer-review under the responsibility of the organizing committee of the ICMB21.
\end{abstract}

Keywords: Bio-Based Insulation; Wood Frame Construction; Moisture Infiltration; Thermal Performance; Durability; HAM-simulation

\section{Introduction}

In Europe, $40 \%$ of the total energy requirements relates to the energy consumption of the construction sector. The awareness resulted in the demand of a building stock which is renewable, circular and incorporates a small-carbon-footprint [1]. Growable materials such as wood, cellulose, straw, textile, cotton and cork, gain interest to replace the traditional building materials. However, because of the natural origin of bio-based materials, an exposure to moisture and unfavorable temperatures, could lead to higher concentrations of insects, fungi or bacteria. The latter could initiate the growth of mould or start the degradation of the cell structures. As the share of bio-based materials rises in the building stock, one should secure their durability by analyzing the moisture and temperature gradients. In addition, materials of natural origin have the ability to store and release moisture over time. Due to this buffering property, a controlled indoor climate is realized as a beneficial indoor humidity is created by reducing peak values [4]. However, the ability to store excess moisture could endanger the thermal performance of the insulation, since thermal conductivity is related to the moisture content. Both risks, regarding the durability and the thermal properties, should be minimized by a correct design but, during construction, poor workmanship or imperfections still might occur. A poorly executed weathering seal or imperfections at the location of the air sealant could respectively cause rain infiltration or infiltration of humid indoor air.

The aim of this study is twofold: the first objective is to gain a better perspective in the different bio-based insulation materials, ready to use in HAM-simulation software. The second objective focusses the evaluation of the buffering property of bio-based insulation materials in a wood frame wall approach, to reduce the effect of united moisture sources. The latter evaluates the impact on durability as well as on thermal performance of walls subjected to different severity of leakage. This way, a moisture control strategy, to preserve the durability and energy saving performance of buildings with bio-based materials could be developed.

\section{Methodology}

In the first phase (I), the emphasis is on the characteristics of several bio-based insulation materials. A summary of the available properties is made through a comprehensive literature study. Mineral wool, cellulose, flax and alterations in the original cellulose material, to incorporate a change in e.g. density, CE, moisture retention, are used in HAM modelling to compare their different hygrothermal performances. The simulations are performed with Delphin 5.9, focusing on typically wood frame walls in Belgium.

In the second phase (II), the moisture behaviour of cellulose is compared to mineral wool in a wider range of wood frame wall constructions and moisture loads. The used parameters and their references are summarized in Fig (a) for both phases. Three different finishes were analyzed: cladding, masonry and an ETICS system, represented in Fig (b).

To analyze the durability of the wall assembly, several prediction models for decay, such as the improved VTT-model, Time of Wetness model regarding mould as well as wood rot [2], Dose Response model [3], are calculated on the different material surfaces of the wall assembly. For the thermal performance, the percentual increase of heat flux in reference to a perfect wall without unintended moisture sources (reference assembly), is calculated over the heating season from September until May.

The unintended moisture sources (UMS) are introduced as moisture sources [5] at the exterior of the insulation. In that location, the rain would infiltrate as a result of an incomplete weathering seal and there, due to its colder temperature the leaked humid indoor air will condensate. The condensation was simulated with the built-in function of Delphin based on WTA 6.2 [6]. 


\section{ICMB21}

(a)

\begin{tabular}{llllll}
\hline Parameter & $\#$ & Values & & Phase & Reference \\
\hline Insulation I & 12 & MW, Cell, Flax,... & {$[-]$} & I & Delphin and WUFI \\
Insulation II & 2 & Mineral Wool, Cellul lose & {$[-]$} & "I & Delphin \\
Insulation Thickness & 2 & 184,300 & {$[\mathrm{~m}]$} & I and II & \\
Ventilation rate cavity (ACH) & 3 & $(100,200,400) ;(1,5,10) ; 0$ & {$[1 / \mathrm{h}]$} & I and II & Jelle (2015) [7] \\
UMS interior & 5 & $1,3,6,30,342$ & {$\left[\mathrm{~m}^{3} / \mathrm{m}^{2} \mathrm{~h}\right]$} & I and II & Jelle (2013) [8];Kunzel (2014) [9] \\
UMs exterior & 4 & $0,1,3,6$ & {$[\%]$} & I and II & Steeman (2020) [10] \\
Orientation & 4 & $45,135,225,315$ & {$[0]$} & II & \\
Indoor Climate & 4 & $25-55 ; 30-60 ; 35-65 ; 40-70$ & RH [\%] & II & DIN EN 15026 \\
Technical cavity & 2 & Air, Insulated & {$[-]$} & II & \\
\hline
\end{tabular}

(b)

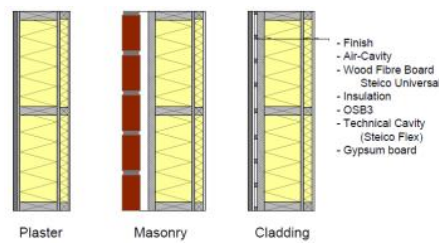

(c)

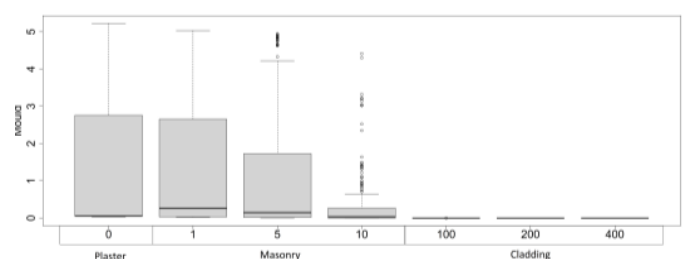

(e)

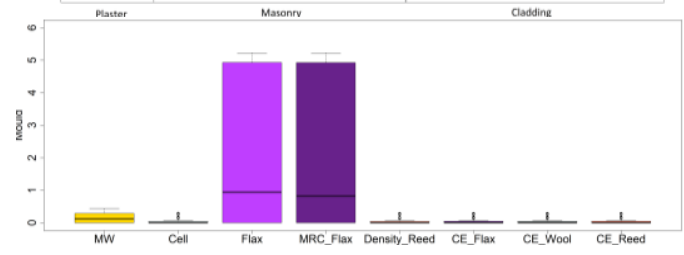

(d)

(f)

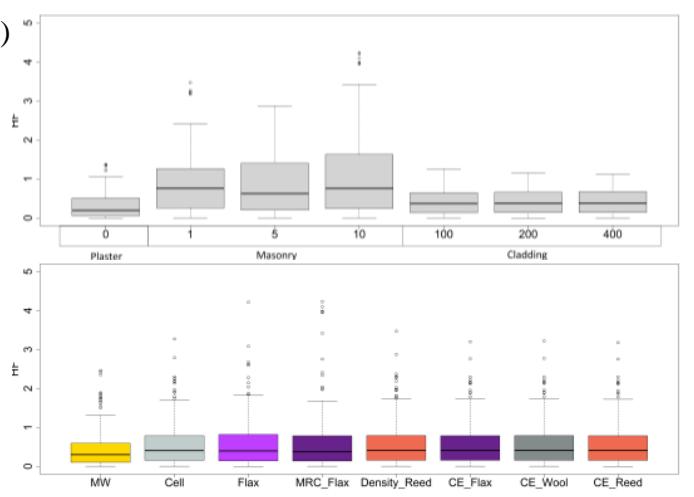

Figure 1. (a) Parameters used in the sampling with references; (b) Setup summary for three types of wood frame walls; (c) Mould Index on OSB surface in relation to ACH for all insulation types; (d) Heat Flux increase in relation to ACH 8 different insulations [\%]; (e) Mould Index on OSB for all insulation types; (f) Heat flux increase for all insulation types [\%]

\section{Results}

Figures (c) and (d) show how the ventilation rate in the cavity is crucial for the severity in mould growth and increase of heat flux (HF). The best results can be noticed for a cladding finish, with ACH between 100-400 1/h. The ETICS system (ACH 0 1/h) shows atypical behaviour for HF increase in Fig (d), the impact by increasing leakage was found to be neglectable as a perfectly sealed wall already exhibited an almost saturated moisture content. For the two types of UMS, the moisture sources related to the leakage in the weathering seal seemed more dominant then the leakages occurring at the air-tightness of the wall construction.

Fig (e) focusses on the influence of different insulation on the mould growth on the inner OSB layer. High absorptive bio-based insulation, such as flax, showed considerably larger degradation. Mainly because more moisture is redistributed towards the OSB sheet and is buffered for a longer time. Mineral wool shows higher degradation risk then cellulose since the vapor diffusion resistance is lower and cellulose reduces humidity peaks by buffering them over its thickness. Fig (f) shows a higher increase of HF for bio-based insulation, since they store moisture for a longer time resulting in a higher thermal conductivity of the material.

\section{Discussion and Conclusion}

During the research, two restrictions were noticed. First, only a handful bio-based materials are available for HAM-modeling, hampering the development of a reliable hygrothermal analysis. For future work, the authors propose a Latin Hypercube sampling to incorporate the wide variety of bio-based materials. Secondly, the quantification of the unintended moisture sources is not yet validated and the air leakage simulated by Delphin does not consider wind pressure effects, only stack pressure is included.

Overall, there is a lower growth of mould in walls when a cladding finish is used, which relates to the high ventilation rate in the air cavity. Due to the buffering of moisture, bio-based materials exhibit the largest decrease in their thermal performance.

In phase II, the performance of cellulose compared to MW is evaluated for a larger number of parameters as shown in Fig (a), subjected to the same unintended moisture sources.

Acknowledgment: The author greatly acknowledges the support and finance of the Flanders Innovation \& Entrepreneurship (HBC.2019.2011)

\section{References}

[1] Zhao, J., Grunwald, J., Ruisinger, U., Feng, S. (2017), Evaluation of capillary-active mineral insulation systems for interior retrofit solution. Build. Env., 115

[2] Viitanen H., Ojanen, T. (2007). Improved model to predict mold growth in building materials. Thermal performance of the exterior envelopes of whole buildings $\mathrm{X}$.

[3] Brischke, C., Meyer-Veltrup, L. (2015), Modelling timber decay caused by brown rot fungi', Materials and Structures. Springer Netherlands

[4] Korjenic, A. Petránek, V. Zach, J. \& Hroudová J., (2011) Development and performance evaluation of natural thermal-insulation materials composed of renewable resources. Energy and Buildings. 43(9), 2518-2523.

[5] Carbonez, K., Van Den Bossche, N., Ge, H., Janssens, A., (2015) Comparison between uniform rain loads and point sources to simulate rainwater leakage with commercial HAM-models, ISBP2015

[6] WTA-Guideline 6-2 (2013) Simulation wärme- und feuchtetechnischer Prozesse. Draft Oct. 2013.

[7] Langmans, J., Desta, T. Z., Alderweireldt, L., Roels, S., (2015), Experimental analysis of cavity ventilation behind residential rainscreen cladding systems,

[8] Langmans, J., Klein, R., Roels, S. (2013). Numerical and experimental investigation of the hygrothermal response of timber frame walls with an exterior air barrier. Journal of Building Physics, 36 (4), 375-397.

[9] Künzel, H. M. (2014), Accounting for unintended moisture sources in hygrothermal building analysis, Fraunhofer-Institute for Building Physics, Germany

[10] Steeman, M., Van Den Bossche, N., Calle, K., (2020) Drying Potential of Wood Frame Walls Subjected to Accidental Water Infiltration, XV International Conference on Durability of Building Materials and Components 